\title{
Agrobacterium tumefaciens T-DNA mediated transformation of Epichloë festucae
}

\author{
A. TANAKA ${ }^{1}$, R.E. WRENN ${ }^{1}$, D. TAKEMOTO ${ }^{1,2}$ and B. SCOTT ${ }^{1,2}$. \\ ${ }^{1}$ Centre for Functional Genomics, Institute of Molecular BioSciences, Massey University, Private Bag 11 222, Palmerston North, \\ New Zealand \\ National Centre for BioProtection, Massey University, Private Bag 11 222, \\ Palmerston North, New Zealand \\ d.b.scott@massey.ac.nz
}

\begin{abstract}
Although much is known about the signals and mechanisms that lead to pathogenic interactions between plants and fungi comparatively little is known about fungal-plant mutualistic symbiotic interactions. The association between Epichloë festucae and perennial ryegrass is a powerful experimental system to understand the molecular basis for fungal-plant mutualistic interactions. We have adopted a forward genetics approach to dissect this symbiosis. Previously we described the use of plasmid mutagenesis to isolate a symbiotic mutant. We describe here the development of an Agrobacterium tumefaciens mediated T-DNA transformation system for E. festucae.
\end{abstract}

Keywords: Epichloë festucae, Agrobacterium tumefaciens, TDNA, transformation

\section{Introduction}

In the association between E. festucae and perennial ryegrass the endophyte grows systemically in the intercellular spaces of vegetative and reproductive tissues as infrequently branched hyphae parallel to the axis of the leaf (Tan et al. 2001; Christensen et al. 2002). Growth of the hyphae is strictly intercellular and synchronised with that of the host grass throughout the life cycle of the plant. To identify E. festucae genes that are required for the establishment and maintenance of a mutualistic interaction with the grass host we have initiated a forward genetics approach (mutant phenotype to gene) to isolate mutants that disrupt this highly regulated symbiosis. In a plasmid mutagenesis screen using the technique of restriction enzyme-mediated integration (REMI) (Schiestl \& Petes 1991) we isolated an E. festucae mutant (FR2) that induces a stunting phenotype and premature senescence of the host grass (Tanaka et al. 2006). While this mutant was the result of single site plasmid insertion that was linked to the mutant phenotype, REMI frequently results in multiple-copy and multi-site integrations and the generation of untagged deletions in the fungal genome (Michielse et al. 2005; Elliott \& Howlett 2006). The development of Agrobacterium tumefaciens mediated T-DNA mutagenesis in filamentous fungi (Bundock et al. 2002; de Groot et al. 1998) overcomes many of these limitations as the insertions are frequently single copy and when deletions are generated they tend to be small (Elliott \& Howlett 2006). The aim of this work was to develop A. tumefaciens mediated T-DNA mutagenesis in E. festucae as an alternative to REMI to generate symbiotic mutants.

\section{Methods}

Biological material and growth conditions

Cultures of Epichloë festucae wild-type strain F11 were grown on $2.4 \%$ potato dextrose (PD) agar at $22^{\circ} \mathrm{C}$. A. tumefaciens strain EHA105 (PN1828; Rif $^{\mathrm{R}}$ ) containing a disarmed agropine plasmid, pTiBo542, (Hood et al. 1993) plus either pBSYT6 (PN1976) or pBSYT7 (PN4015), were grown in either LB or IM medium at $28^{\circ} \mathrm{C}$ and where appropriate supplemented with rifampacin $(50$ $\mu \mathrm{g} / \mathrm{ml})$ or kanamycin $(50 \mu \mathrm{g} / \mathrm{ml})$. Escherichia coli strain DH5 $\alpha$ was used for all plasmid transformations using ampicillin (50 $\mu \mathrm{g} / \mathrm{ml}$ ) for selection.

Induction medium (IM) contained per litre: $0.01 \mathrm{M}$ $\mathrm{K}_{2} \mathrm{HPO}_{4} .3 \mathrm{H}_{2} \mathrm{O}, 0.01 \mathrm{M} \mathrm{KH}_{2} \mathrm{PO}_{4}, 2.57 \mathrm{mM} \mathrm{NaCl}, 9 \mu \mathrm{M}$ $\mathrm{FeSO}_{4} .7 \mathrm{H}_{2} \mathrm{O}, 3.78 \mathrm{mM}\left(\mathrm{NH}_{4}\right)_{2} \mathrm{SO}_{4}, 10 \mathrm{mM}$ glucose, $0.7 \mathrm{mM}$ $\mathrm{CaCl}_{2}, 2 \mathrm{mM} \mathrm{MgSO}_{4}$, glycerol $(0.5 \%)$, buffered to $\mathrm{pH} 5.3$ with $40 \mathrm{mM}$ 2-[N-Morpholino] ethanesulfonic acid (MES) (Bundock et al. 2005).

\section{Molecular biology}

Genomic DNA from E. festucae was isolated from freeze-dried mycelium using previously described methods (Yoder 1988). Genomic digests separated by electrophoresis were transferred to positively charged nylon (Roche) membranes by capillary transfer and DNA fixed by UV-crosslinking. The filters were probed with $\left[\alpha{ }^{-32} \mathrm{P}\right]$-dCTP $(3000 \mathrm{Ci} / \mathrm{mmole}$, Amersham) labelled probes and signals detected as previously described (Young et al. 1998).

\section{Vector construction}

Plasmid pYT6 $\left(\operatorname{Kan}^{\mathrm{R}}\right)$ was prepared by Yasuo Itoh by cloning a HindIII/SalI hygromycin resistant gene cassette (PglaA-hph), from pCWHyg1 (Young et al. 1998) into pCAMBIA1380 digested with HindIII/XhoI. . Plasmid pBSYT6 $\left(\operatorname{Kan}^{\mathrm{R}}, \mathrm{Amp}^{\mathrm{R}}\right)$ was prepared by cloning a BamHI/SpeI digest of pBlueScript KS+ into $B g l \mathrm{II} / \mathrm{SpeI}$ digested pYT6. Plasmid pBSYT7 $\left(\operatorname{Kan}^{\mathrm{R}}, \mathrm{Amp}^{\mathrm{R}}\right)$ was prepared by removing the hygromycin resistance cassette from pBSYT6 by digestion with $S a c \mathrm{I} / \mathrm{Xba \textrm {I }}$ and replacing with a SpeI/HindIII geneticin resistance cassette (PtrpC-nptII) from pSF17.1. pSF17.1 was prepared by Simon Foster by ligating a 1.75-kb PCR product containing the PtrpC-nptII-TtrpC cassette from pII99 into SmaI cut pSP72 (Promega). The PCR product was generated by PCR overlap extension to eliminate the $\mathrm{NcoI}$ site in $n p t I I$ and to truncate the PtrpC.

\section{Transformation conditions}

A. tumefaciens strain EHA105 was grown overnight in LB medium at $28^{\circ} \mathrm{C}$, harvested by centrifugation and resuspended in IM medium to A600 of 0.15 and then grown for a further $6 \mathrm{~h}$

Table 1 Different hyphal growth and morphology classes of T-DNA mutants of $E$. festucae.

\begin{tabular}{lcc}
\hline Phenotype & Number & $\%$ \\
\hline Wild type & 386 & 85.4 \\
Small colony & 13 & 2.9 \\
Reduced aerial hyphae & 37 & 8.2 \\
Increased aerial hyphae & 2 & 0.4 \\
Premature senescence & 14 & 3.1 \\
\hline Total & 452 & 100 \\
\hline
\end{tabular}


Figure 1 Physical maps of PBSYT6 and PBSYT7 vectors used for $A$. tumefaciens mediated T-DNA transfer of E. festucae.

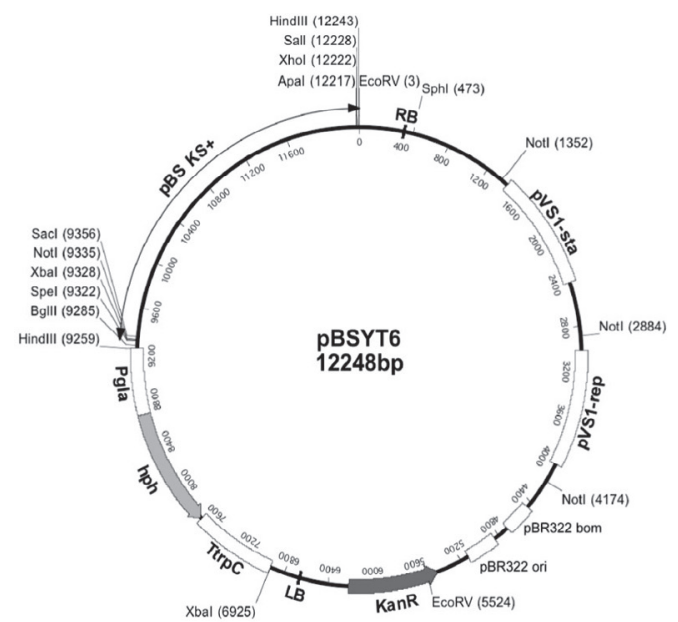

Figure 2 T-DNA transformed hyphae of E. festucae growing on PD agar containing hygromycin.

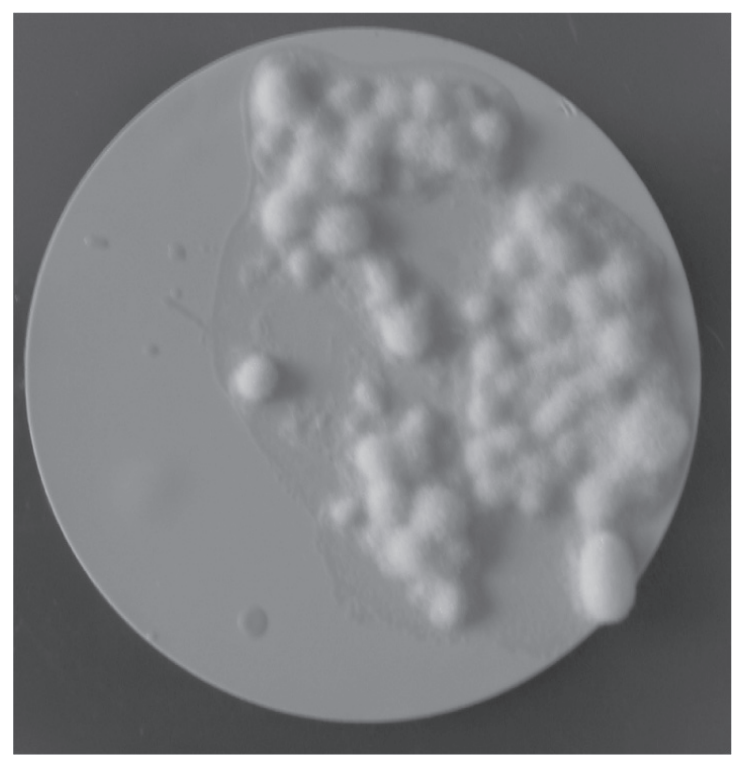

at $28^{\circ} \mathrm{C}$ in the presence of acetosyringone $(200 \mu \mathrm{M})$. Mycelial cultures $(4 \mathrm{ml})$ of $E$. festucae were grown in PD medium in Universal bottles for 6 days at $22^{\circ} \mathrm{C}$, washed twice in $5 \mathrm{ml}$ of IM medium by centrifugation and washing of the pellet, and finally resuspended in $100 \mu \mathrm{l}$ of the $A$. tumefaciens culture. This mixture was then spread on a nitrocellulose membrane (Millipore $0.4 \mu \mathrm{m}$ $\mathrm{HA}, 47 \mathrm{~mm}$ ) on IM agar medium containing acetosyringone (200 $\mu \mathrm{M})$ and incubated at $22^{\circ} \mathrm{C}$ for 2 days. The membrane was then transferred to a PD agar plate containing hygromycin $(150 \mu \mathrm{g} / \mathrm{ml})$ and cefataxime $(200 \mu \mathrm{g} / \mathrm{ml})$ and incubated for a further 14-20 days. The resulting transformants were nuclear purified by sub-culturing mycelium from the edge of a colony to PD medium containing either hygromycin $(150 \mu \mathrm{g} / \mathrm{ml})$, or geneticin $(200 \mu \mathrm{g} / \mathrm{ml})$.

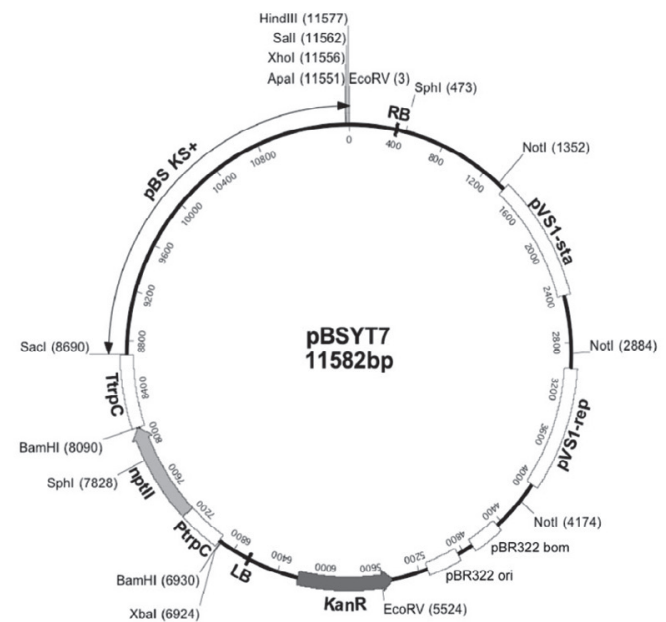

Figure 3 Molecular analysis of T-DNA mutants of $E$. festucae. Southern hybridization of Sstl (Sacl) genomic digests of $E$. fesucae T-DNA mutants numbers Ag352 (lane 1), Ag353 (lane 2), Ag357 (lane 3), Ag358 (lane 4), Ag378 (lane 5), Ag380 (lane 6), Ag396 (lane 7) and Ag397 (lane 8) probed with $\left[{ }^{32} \mathrm{P}\right]$-labelled pBSYT6.
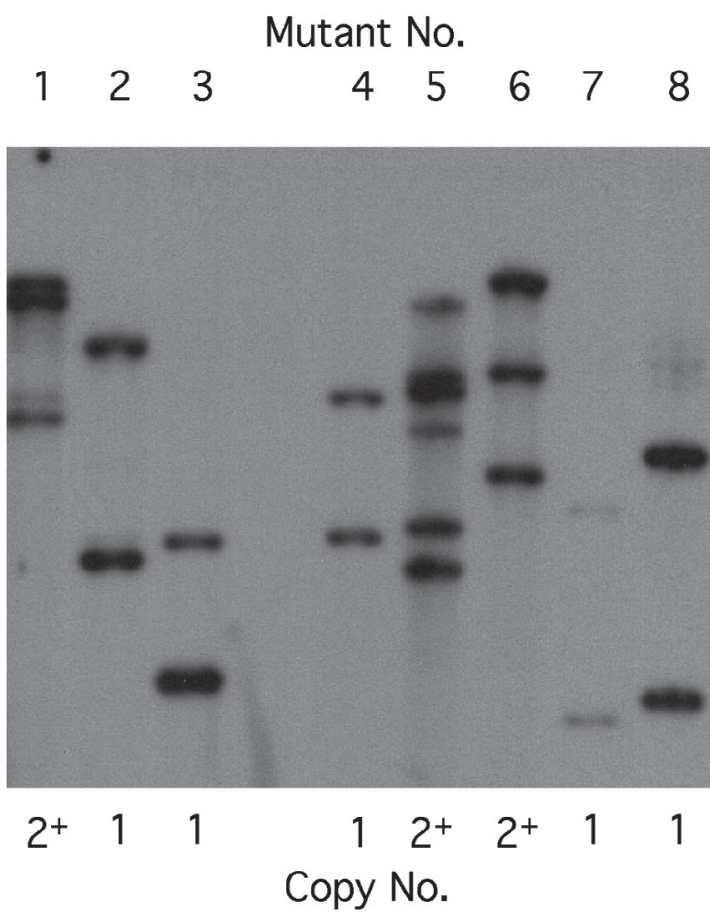

\section{Results}

Two binary vectors, pBSYT6 and pBSYT7, containing fungal selectable markers conferring resistance to hygromycin and gentamycin respectively, were developed for A. tumefaciens mediated T-DNA transformation of E. festucae (Fig. 1). Plasmid 
Figure 4 T-DNA induced colony morphology mutants of E. festucae. Wild-type (A), and T-DNA mutants Ag78 (B), Ag149 (C) and Ag243 (D).

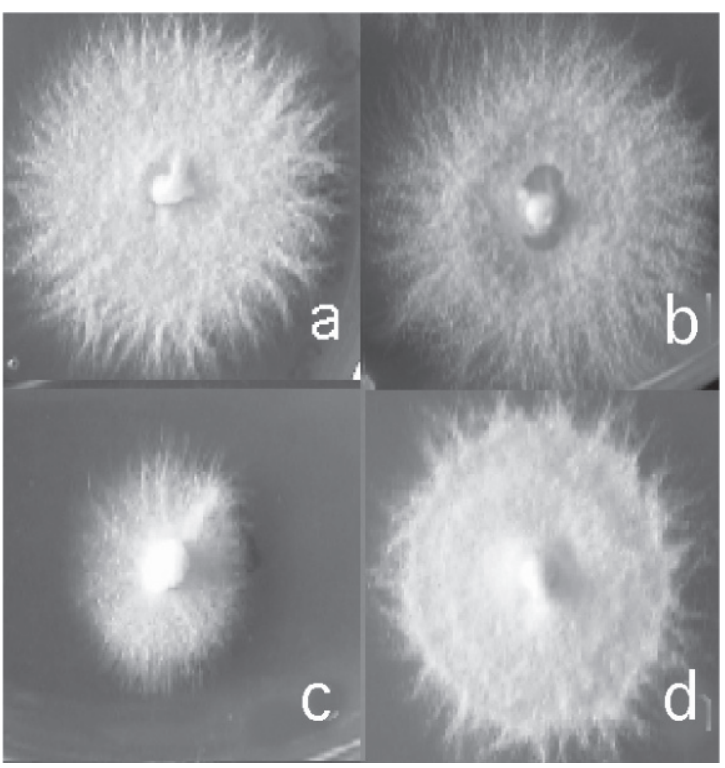

pBSYT6 was constructed by cloning pBlueScript KS+ into pYT6, to provide a ColE1 origin of replication and bacterial selectable marker $\left(\mathrm{Amp}^{\mathrm{R}}\right)$, to facilitate plasmid rescue in E. coli of T-DNA junction sequences containing E. festucae DNA. Plasmid pYT6 contains a hygromycin resistance cassette between the left and right $\mathrm{T}$-DNA borders, a $\mathrm{Kan}^{\mathrm{R}}$ bacterial selectable marker, pBR322 (ColE1) origin of replication (ori), the cis acting site required for conjugational transfer (bom; basis of mobility), and the pVS1-rep and pVS1-sta sequences, which confer stability to the plasmid in an A. tumefaciens background, even under nonselectable conditions (Deblaere et al. 1987). Plasmid pBSYT7 was constructed by replacing the hygromycin resistance cassette in pBSYT6 with a geneticin resistance cassette from pII99.

Incubation of $E$. festucae hyphae with $A$. tumefaciens strain EHA105 containing a disarmed derivative of the agropine type Ti plasmid, pTiBo542, and pBSYT6, gave rise to numerous $\mathrm{Hyg}^{\mathrm{R}}$ colonies after incubating the mating mixture at $28^{\circ} \mathrm{C}$ for about 2 weeks (Fig. 2). Following nuclear purification of these transformants by sub-culturing the edge of the growing colony onto fresh selectable medium, DNA was isolated from a selection of eight arbitrarily chosen transformants, and a Southern blot of an Sst I digest probed with pBSYT6 (Fig. 3). Five of the eight (63\%) transformants examined had a single copy T-DNA insertion, and each insertion was at a unique site in the genome.

A collection of 452 T-DNA mutants was generated and the hyphal morphology and growth of each classified into one of four different phenotypes (Table 1). 66/452 (14.6\%) of the mutants were altered in either colony growth or morphology compared to wild-type (Fig. 4A), and included reduced aerial hyphae (Fig. 4B), smaller colony size (Fig. 4C), increased aerial hyphae (Fig. 4D) and premature senescence (not shown).

\section{Discussion}

We describe here the development of a method to generate $A$. tumefaciens T-DNA induced mutants of E. festucae. Many filamentous fungi are now amenable to this transformation method (Michielse et al. 2005). For the method to be effective as a mutagenesis system it is essential that insertion is relatively random. From the small number of transformants examined to date it would appear that each E. festucae mutant had the T-DNA integrated at a unique site, with around $63 \%$ having a single copy insertion. Single copy insertions are the preferred outcome for genetic analysis and molecular rescue of the flanking $E$. festucae sequences. However, it is also important that the mutant phenotype is linked to the T-DNA insertion. Genetic analysis of a large set of T-DNA induced mutants from Cryptococcus neoformans demonstrated that just $50 \%$ of the mutants showed linkage (Walton et al. 2005). In the same study they showed that there was a bias toward insertions into promoters of the genes, a result consistent with what has been observed in Arabidopsis thaliana (Alonso et al. 2003; Pan et al. 2005) Despite this limitation, insertions in the promoter region frequently give rise to mutant phenotypes. Recently, Elliott \& Howlett (2006) reported the isolation of a T-DNA induced mutant of Leptosphaeria maculans that had reduced pathogenicity. Molecular analysis showed that the single copy insertion in this mutant was located in the promoter region of two bi-directionally transcribed genes; encoding an alcohol dehydrogenase-like gene $(A d h 4 L)$ and a 3ketoacyl-CoA thiolase (Thiol). Ectopic expression of the Thiol gene recapitulated the mutant phenotype, indicating that T-DNA induced alteration of expression of this gene was responsible for the pathogenicity defect.

The isolation here of E. festucae morphological mutants demonstrates that T-DNA mutagenesis will be a useful method for tagging and isolating genes important for the symbiotic interaction between $E$. festucae and perennial ryegrass.

\section{ACKNOWLEDGEMENTS}

This research was supported by grants from the Tertiary Education Commission (National Centre for BioProtection Centre of Excellence), the Royal Society of New Zealand Marsden Fund (MAU103) and the New Zealand Foundation for Research, Science and Technology (C10X0203). The authors thank Andrea Bryant (Massey University), and Michael Christensen, Wayne Simpson and Anouck De Bonth (AgResearch), for technical assistance. We thank Yasuo Itoh (Shinshu University, Japan) and Simon Foster (Massey University) for construction of pYT6 and pSF17.1, respectively.

\section{REFERENCES}

Alonso, J.M.; et al. 2003. Genome-wide insertional mutagenesis of Arabidopsis thaliana. Science 301: 653-657.

Bundock, P., den Dulk-Ras, A.; Hooykaas, P.J.J. 1995. Transkingdom T-DNA transfer from Agrobacterium tumefaciens to Saccharomyces cerevisiae. European Molecular Biology Organisation Journal 14: 3206-3214.

Christensen, M.J.; Bennett, R.J.; Schmid, J. 2002. Growth of Epichloë/Neotyphodium and p-endophytes in leaves of Lolium and Festuca grasses. Mycological Research 106: 93-106.

Deblaere, R.; Reynaerts, A.; Hofte, H.; Hernalsteens, J.P.; Leemans, J.; van Montagu, M. 1987. Vectors for cloning in plant cells. Methods in Enzymology 153:277-292.

de Groot, M.J.A.; Bundock, P.; Hooykaas, P.J.J.; Beijersbergen, A.G.M. 1998. Agrobacterium tumefaciens-mediated transformation of filamentous fungi. Nature Biotechnology 16: $839-842$

Elliott, C.A.; Howlett, B.J. 2006. Overexpression of a 3-ketoacylCoA thiolase in Leptosphaeria maculans causes reduced pathogenicity on Brassica napus. Molecular Plant-Microbe Interactions 19: 588-596.

Hood, E.E.; Gelvin, S.B.; Melchers, L.S.; Hoekema, A. 1993. New Agrobacterium helper plasmids for gene transfer to 
plants. Transgenic Research 2: 208-218.

Latch, G.C.M.; Christensen, M.J. 1985. Artificial infection of grasses with endophytes. Annals of Applied Biology 107: 17-24.

Michielse, C.B.; Hooykaas, P.J.J.; van den Hondel, C.A.M.J.J.; Ram, A.F.J. 2005. Agrobacterium-mediated transformation as a tool for functional genomics in fungi. Current Genetics 48: 1-17.

Pan, X.; Li, Y.; Stein, L. 2005. Site preferences of insertional mutagensis agents in Arabidopsis. Plant Physiology 137: 168-175.

Schiestl, R.H.; Petes, T.D. 1991. Integration of DNA fragments by illegitimate recombination in Saccharomyces cerevisiae. Proceedings of the National Academy of Sciences USA 88: 7585-7589.

Tan, Y.Y.; Spiering, M.J.; Scott, V.; Lane, G.A.; Christensen, M.J.; Schmid, J. 2001. In planta regulation of extension of an endophytic fungus and maintenance of high metabolic rates in its mycelium in the absence of apical extension. Applied and Environmental Microbiology 67: 5377-5383.

Tanaka, A.; Christensen, M.J.; Takemoto, D.; Park, P.; Scott, B. 2006. Reactive oxygen species play a role in regulating a fungus-perennial ryegrass mutualistic association. The Plant Cell 18: 1052-1066.

Walton, F.J.; Idnurm, A.; Heitman, J. 2005. Novel gene functions required for melanization of the human pathogen Cryptococcus neoformans. Molecular Microbiology 57: 1381-1396.

Yoder, O.C. 1988. Cochliobolus heterostrophus, cause of southern corn leaf blight. Advances in Plant Patholology 6: 93-112.

Young, C.; Itoh, Y.; Johnson, R.; Garthwaite, I.; Miles, C.O.; Munday-Finch, S.C.; Scott, B. 1998. Paxilline-negative mutants of Penicillium paxilli generated by heterologous and homologous plasmidintegration. CurrentGenetics 33:368-377. 